\title{
Accounting Adjustments on the Discounted Free Cash Flow Valuation Model for Appraising SMEs in Greece
}

\author{
Athanasios D. Karampouzis, Dimitrios Ginoglou \\ University of Macedonia, Thessaloniki, Greece
}

\begin{abstract}
The present paper examines accounting issues that come up when evaluating a private firm under the Greek accounting standards. More specifically, we try to provide an accounting framework for appraisers who, when they try to retrieve intrinsic values of SMEs, make use of the Free Cash Flows to the Firm (FCFF) model. We focus on adjusting the firms' statements' items in order to produce a nominator that is consistent with the FCFF theory, taking in response-among others—-the Greek tax legislation and the Greek General Chart of Accounts. Finally, we produce a rather normative formula, which can be positively used upon this very model (FCFF valuation) in order to assess the value of a private firm in Greece. The formula is explained thoroughly enough via a practical example of a real Greek private firm.
\end{abstract}

Keywords: firm valuation, private firm, FCFF, taxation

\section{Introduction}

Valuation of a firm via discounted free cash flows to the firm is a common way to evaluate a non-public enterprise, because of the flexibility that offers. Free cash flows to the firm are cash flows available to the potential investor (especially in cases of mergers, acquisitions, audit etc.) after deduction—from net income - of investments in fix and working capital, after addition of net non-cash charges and after-tax interest charges. This simple theorem gets more complicated when different accounting systems provide different information about the same items.

What motivated us to research accounting and taxation issues applied on the valuation model of FCFF is the lack of research on the field for Greek firms. While there have been several research on valuating public companies, there have been an inadequate number of papers and articles when it comes to private firms. As the main reason for this fact we consider to be the complexity of the Greek accounting and taxation scheme, which make the compliance with the main theory hard.

The methodology we use to accomplish our goal is rather normative, since we try to adjust certain accounting items so that they converge to the discounted FCFF theory. Our effort for contribution in research lies upon the adjustments we make in order to comply with the discounted FCFF model. We try to produce a pro forma model useful for any further research on appraising Greek private firms that uses the discounted FCFF model.

Athanasios D. Karampouzis, Ph.D. candidate, University of Macedonia, Thessaloniki, Greece.

Dimitrios Ginoglou, professor, University of Macedonia, Thessaloniki, Greece.

Correspondence concerning this article should be addressed to Athanasios D. Karampouzis, El. Venizelou Str. 22, 54624, Thessaloniki, Greece. 


\section{The Discounted FCFF Model and Accounting Issues}

In order to use the discounted FCFF model, two components are of necessity to be calculated: the free cash flow to the firm and a discount rate- the WACC. The free cash flow formula (the nominator) is described below:

$$
\text { FCFF }=\text { NetInc }+ \text { NetNonCashCharges }+ \text { Int(1-t) }- \text { InvFixCapital }- \text { InvWorkingCapital }
$$

Net Income can be easily retrieved from the firm's Income Statement, assuming that all revenues and expenses are fully depicted in the Statement. Net non-cash charges are items in the Statement that may decrease earnings, but do not require an outlay of cash. The most common case of such impairment is depreciation expenses of fixed capital. Due to the fact that such charges are not operational outflows, they are added back to net income to depict the real cash flow picture to the investor. Following a similar reasoning, after-tax interest is also added back to net income.

The Investment in Fixed Capital that is deducted from net income is actually the percentage increase in fixed capital form one financial year to the next that required funding and, of course, is not included as an expense in the Income Statement, but rather as an Asset in the Balance Sheet. As such items imply cash or cash equivalent charges they should be included in the calculation of FCFF. Investments in Working Cpital (increases in inventory, accounts receivables etc., or decreases in accounts payable, short-term debt etc.) also conceal cash or cash equivalent charges and should, therefore, be included as a decreasing item during calculation of FCFF, as well.

In order to get the present value of FCFF, it is necessary to discount them. WACC is used as a discount rate, because it expresses the opportunity cost that the capital providers of the enterprise have to pay. Assuming a firm is financed by the two main sources of finance, equity and debt, WACC can be calculated by the following formula:

$$
W A C C=\frac{D e b t}{D e b t+\text { Equity }} r_{d}(1-T)+\frac{\text { Equity }}{\text { Debt }+ \text { Equity }} r
$$

where, $r_{d}$ refers to the cost of debt and can be calculated taking in account the current rate of the bonds of the firm or other forms of debt that the firm may be financed by, such as bank loan rates etc. $r_{d}$ has to be adjusted to reflect the real cost of debt, because the interest that a firm pays is tax deductible and, as a result, the firm is benefited by financing itself by debt. The adjustment is to take in account the after-tax cost of debt. $r$ refers to the cost of equity. Cost of equity is the required rate of return by the investors and can be derived from models like the CAPM, the APT etc. Finally, the percentage between debt and equity reflects the capital structure of the firm. Since it is not always stable through time, the perfect capital structure can be used in order to calculate WACC (Farber, Gillet, \& Szafarz, 2006). Going further, in order to calculate the present value of the firm the following formula is used (Tham \& Vélez-Pareja, 2004):

$$
v_{0}=\sum_{t=1}^{\infty} F C F F_{t} /(1+W A C C)^{t}
$$

Following the reasoning of the Gordon growth model of dividend discounting, assuming a constant rate of growth (g) is assumed, and the above equation transforms as:

$$
v_{0}=\left[F_{C F F_{0}}(1+g)\right] /(W A C C-g)
$$

where 


$$
F C F F_{t}=\text { FCFF }_{t-1}(1+g)
$$

The main model comes as presented above. However, when it comes to private firms, there are a few special issues that need to be taken into account. In this section our analysis is based on the surveys of Feldman (2005), Bajaj, Denis, David, Ferris, and Sarin (2001) and Damodaran (2005) on appraising private companies. The four key elements utilized for valuation of private companies are: the cost of capital, cash flows discounted, adjustments on value due to the lack of market information (discount for lack of marketability) and adjustment on value (control premium), because of admission of the investor in the company management (depending on the legal framework of the country).

As private firm shares are not traded on a stock exchange, the cost of equity cannot be easily derived. Instead there has to be an indirect method of calculation. This method suggests the initial calculation of the average beta of public companies in the same industry, which are comparable to the private company. The assumptions that are made about which companies are comparable enough and plenty, because the analyst has to take into account all activities of the company and use even public companies in adjacent industries, using a broad interpretation of the concept of economic sector. Having calculated the average coefficient beta, then calculated the average tax rate and the average debt-to-equity ratio of foreign capita. This is how the average unlevered beta is calculated:

$$
\beta_{\text {unlev }}=\beta / 1+(1-T)\left(\frac{D}{E}\right)
$$

After that, the beta can be easily derived:

$$
\beta_{\text {priv }}=\beta_{\text {unlev }}\left[1+\left(1-T_{\text {priv }}\right)\left(\frac{D}{E}\right)\right]
$$

At this point, it is assumed that the debt-to-equity ratio of the company will converge in the short term with the corresponding average ratio of the industry. Alternatively, the ratio can be calculated as the objective of the management, as estimated by the analyst, of course. In each case the beta of the firm is calculated according to the average beta of companies in the sector or adjacent industries. If historical data of the firm are many, then the returns (calculated using fundamentals) are to be regressed with market returns of the industry or with the returns using a composite index. From the resulting regression a coefficient occurs, which is the beta of the private company. In both cases_and comparable accounting beta-the risk exists that the estimation is biased to some extent, as in the first case the assumptions may simply be not applicable, while in the second case bias may stem from the poor quality of accounting data.

Eventually, cost of capital can be calculated. Should, however, the assumptions made in each case to be consistent with each other, for example if the assumption followed that the cost of capital converges to and thus coincides with the industry average (listed companies), the same assumption should be made as far as the cost of debt is concerned.

The second key element in evaluating a private firm is discounted cash flows. Cash flows in this case show specific features that hinder their accurate depiction in a valuation analysis. These characteristics may be: different accounting standards and norms from country to country (therefore, requires a good knowledge of accounting framework and legislation by the analyst), mixture of personal with business expenses in the accounts in many cases (an attribute of sole proprietorships), and ambiguity in the distinction between dividends and salary for managers of private companies, which they are practically owned by them.

Thirdly, the fact that the company is not public creates fewer opportunities to raise capital, which, undoubtedly, affects its value. For this purpose, the value should be subject to appropriate adjustments. These 
adjustments are operated with the help of a qualitative discount factor (discount for lack of marketability), which depends on other factors, like how liquid the assets of the company are, the size of the firm, whether it presents healthy financial situation, compared to the industry, the volume of gross cash flows (sales) produced by the enterprise as a result of its activity etc. Calculation is usually a regression of what the analyst considers that express these concepts (for example, health of the firm can be set the amount of net income, with appropriate adjustments) with a measure that acts as an impairment factor and can be for example the price of the restricted stock etc. (Damodaran, 2005), where data come from the firm's statements (fundamentals).

The fourth and final element of significance for the valuation of a private company is the control of management. The value of control premium in a private company stems from the fact that usually the main shareholder holds all managerial decisions of the firm, in a manner that management and property do match. Control premium consists of two factors. The first one relates to the possibility of a change managerial control withdrawing the potentially inefficient old management. To determine this possibility certain factors should be taken into account, such as legal restrictions on control exercise in cases of acquisitions, the percent of capital that remains in the hands of the current management, the rate of votes on the board of directors in relation to the shares etc. A second factor relates to the value of the acquisition of control in the company and can be split into two components. The first one is the present value of the new managerial decisions, in relation to the former ones, while the latter one concerns the collateral benefits of the change in administration, such as reputation for renewal, which may be translated consumer curiosity and buzz, therefore a potential increase in cash flow, etc. The first component clearly depends on the quality of decisions made by the current management so far, while the latter depends not only on the legal right to control, but on convenience to exert real and effective control.

After having presented the main model and its private firms' implications we have to mention in brief certain accounting issues regarding appraisals (under IFRS or US GAAP). Valuation methodology in general makes certain assumptions, in order to be more practical in terms of implementation. An assumption of the highest importance is the quality of published financial statements, since they are the source of every fundamental element taken into account. All matters relating to the reliability of the financial statements are part of the overall thematic called quality of earnings.

A basic accounting principle that is often disturbed by accounting standards themselves is the clean surplus principle. This particular principle demands that net income reflects all changes occurred in net worth, except from transactions with shareholders (dividends, buybacks etc.) (Feltham \& Ohlson, 1995). The principle is disturbed by the accounting framework itself in several countries and on IAS. Disruption is fact when certain liabilities, revenues or expenses (non-operating, mainly) items may not be depicted in the balance sheet and kept outside the accounting cycle, even in a separate one. Such items may be adjustments arising from exchange differences, changes in fair value of financial derivatives (Frankel \& Lee, 1998) etc.

Following the same pattern, there are cases where the exploitation of special cash or cash equivalent accounts retained by the firm is able to cover extraordinary events that may occur and to create extraordinary expenses, such as fire in uninsured goods etc. (cookie jar accounting). This sort of exploitation can lead to distortion of the real value of the firm (Schilit, 2010). The result in this case is that the firm shows steady gains, even in years when operating profit is reduced or even below zero, reducing artificially the risk for a potential investor.

Finally, in cases of acquisitions the question of goodwill and goodwill impairment is raised. Goodwill arises when a company is acquired by another and the price is higher than the fair value (total assets minus total equity). Goodwill is stated on the assets of the business and the management reserves the right to impair it 
unless it determines that the fair value is lower than the historical cost (Lhaopadchan, 2010). Impairments reduces net income, thereby reduces the value of the firm, so the analyst must make appropriate adjustments where necessary to ensure the comparability of the company's value to the value of other firms to facilitate investors in taking decisions.

\section{The Greek Accounting and Taxation System}

The Greek accounting scheme is rather law- than principle-oriented, pretty much like other continental schemes. The basic legislation corpus includes the corporation act No. 2190/1920 and the Greek General Chart of Accounts (GGCA) act No. 1123/1980. However, since legislation often intervenes in accounting issues, the general chart has been constructed in such a way in order to incorporate every change in tax law. As a result, tax laws intervene in extracting the final result of firms in a way that may differ from year to year.

In fact, there are specific tax laws and ministerial orders that change rates of depreciation or even change whole accounting issues year by year and in a way that an appraiser of private firms finds it hard to be accurate enough when adjusting such items. Moreover, the different structure of tax depiction upon the statements from the IFRS framework and the complexity of the firm taxation itself reinforce the difficulties of an appraisal and the necessity of the accuracy of adjustments.

To be more specific we will try to explain main aspects of firm taxation over time. First of all, in Greece there are several forms of companies, but what our analysis is concerned, we refer to limited partnership firms and SAs, though not the ones that have gone public. These company forms' statements enjoy a form of publicity, though, through the obligation to publish them in newspapers and/or websites, making the statements reachable for a potential investor. The current main tax law is the No. 4172/2013. In order to calculate the tax base we use the following table of a hypothetical example (Ginoglou, 2014), introducing additionally the reader to the relative terminology:

Table 1

Tax Base Calculation for Greek Private Firms

\begin{tabular}{|l|l|l|}
\hline Increasing tax base & Decreasing tax base & Explanation \\
\hline Net profit & $\begin{array}{l}\text { The final result coming from the Income Statement, without measuring } \\
\text { taxes, though. }\end{array}$ \\
\hline Accounting differences & & Taken in response only for tax calculation. It is not an accounting item. \\
\hline & Revenue from shares & Net gains from financial investments in shares of other firms. \\
\hline & Last years' loss & $\begin{array}{l}\text { This component comes from the right to transfer old losses up to five } \\
\text { financial years ahead, in order to reduce taxation, decreasing the tax base } \\
\text { current. }\end{array}$ \\
\hline Taxable profit (tax base) & & The final tax base (also not an accounting item). \\
\hline
\end{tabular}

The presentation of the Table of Income Distribution follows, a statement that comes after the main Income Statement, where profit is distributed to the state (via taxes) and what is left to the owners or stays in the firm, in order to refinance certain plans and projects.

By deducting all these elements from net profit, we obtain the item distributable profit. The final payable tax is not yet calculated though, there are several other components of it. However, for the appraising purpose the analysis stops with the calculation of the main income tax. The parts excluded from our analysis are regarded as debit of the cash and cash equivalents of the next year, a mixture, actually, of non-cash and cash components. 
Table 2

Table of Income Distribution and Its Items

\begin{tabular}{|l|l|l|}
\hline Increasing profit & Decreasing profit & $\begin{array}{l}\text { Explanation } \\
\text { The final result coming from the Income Statement, without measuring taxes, } \\
\text { though. }\end{array}$ \\
\hline Net profit & $\begin{array}{l}\text { This component comes from the right to transfer old losses up to 5 financial } \\
\text { years ahead, in order to reduce taxation, decreasing the tax base current. }\end{array}$ \\
\hline & Tax auditing differences & An item that includes several elements analyzed in section 4. \\
\hline & $\begin{array}{l}\text { Other taxes, non } \\
\text { regarded as operational } \\
\text { (i.e. real estate taxes) }\end{array}$ & Other taxes, beside main tax (but not all of them). \\
\hline & $\begin{array}{l}\text { Tax base } \times \text { tax rate }= \\
\text { main income tax }\end{array}$ & The main income tax subtracted from net income. \\
\hline
\end{tabular}

\section{The Accounting Adjustments Under the Greek General Charts of Accounts: The Model}

Our attempt here is to produce a model that adjusts accounting items in order to correctly evaluate a private firm. The model our model will apply on is the free cash flow to the firm. Two sets of adjustments are held: the first one contains non-cash items that need to be extracted from the model so as to better depict the free cash flows. The second one includes adjustments that need to be done because of the specifications of the Greek accounting schemes and intervening tax legislation, adjustments unnecessary when a firm under IFRS is about to be appraised. As far as the remaining two components of the model, we consider that there is no difference between the accounting items used to produce them under the GGCA and the IFRS.

Before making those two sets of adjustments we classified certain references on what adjustments should be made, taking in response the IFRS and US GAAP. Furthermore, there are included other adjustments, outside of the accounting framework, like excess owner compensation, that do not affect our analysis. Note that we only match those items that contain a different approach in the GGCA. Other items are just named to give a more complete picture. These adjustments are applicable to every valuation model that contains discounted cash flows, not just discount free cash flows to the firm.

Table 3

Item Adjustments According to References and Application Upon the GGCA

\begin{tabular}{|c|c|}
\hline Type of adjustment & Apply on the GGCA \\
\hline \multicolumn{2}{|r|}{ Leonard Friedman (2014) } \\
\hline Excess owner compensation & - \\
\hline Fair market rent & $\begin{array}{l}\text { Imputed rent cost, that is recognized by the tax authority as deductible and is edited } \\
\text { in the books, although it is a theoretical item that may not have even been revised at } \\
\text { the end of the year as positive accounting difference. It needs access to the books of } \\
\text { the firm in order to be identified. }\end{array}$ \\
\hline Tax depreciation & - \\
\hline Personal expenses & - \\
\hline Travel and entertainment & - \\
\hline Cash base to accrual base adjustments & - \\
\hline Unreported income (tax evasion) & - \\
\hline Non-recurring expenses & $\begin{array}{l}\text { There is a separate item in the Income Statement for these expenses, alongside with } \\
\text { unusual expenses. }\end{array}$ \\
\hline \multicolumn{2}{|l|}{ Frankel and Lee (1998) } \\
\hline Clean surplus relation (CSR) & Not a concept under the GGCA. \\
\hline
\end{tabular}


Table 3 to be continued

\begin{tabular}{|l|l|}
\hline \multicolumn{2}{|c|}{ De Franco et al. (2011) } \\
\hline Underfunded defined benefit pensions & Not a concept under the GGCA. \\
\hline Operating leases & There is no distinction between operating and financial leases. \\
\hline Hybrid securities & - \\
\hline Securitizations & - \\
\hline Capitalized interest & - \\
\hline Employee stock compensation & \\
\hline Unusual and non-recurring items & There is a separate item in the Income Statement for this sort of expenses. \\
\hline Non standard adjustments & - \\
\hline Inventory on a LIFO cost basis & - \\
\hline
\end{tabular}

The two sets of adjustments that were mentioned above are summed up on the table below:

Table 4

Accounting Adjustments, According to the Model of the Present Paper

\begin{tabular}{|l|l|l|l|}
\hline Increasing nominator & Decreasing nominator & Components of (2.1) & Set of adjustment \\
\hline Distributable profit & & Net Income & - \\
\hline Unusual and non-recurring items & & Non-cash charge & Greek accounting and tax schemes \\
\hline Depreciation & & Non-cash charge & Non-cash charge \\
\hline & Tax auditing diff. & Non-cash charge & Greek accounting and tax schemes \\
\hline
\end{tabular}

While all the other adjustments function according to references mentioned above, the reasoning of the adjusted tax auditing differences needs to be further clarified. In the fist it is suggested by (Stowe, 2007), as "a case that needs special attention”. Under the GGCA it means that tax authorities have audited closed financial years and have found discrepancies. Such discrepancies may be reported tax evasion, depreciation more than permitted by the law, which was not accounted as accounting difference in order not to increase the tax base, virtual costs, items that went expensed when they should be capitalized, non-recognizable provisions tax-wise. It may also include court orders for tax issues against the state (it serves as decreasing element of this item, taking a meaning of clearing between it and liabilities against the state). It is rather possible that this item distorts the net income picture as it consists of several elements, that are mean reverting to zero over time (unless the firm has a reported history of non-compliance with tax legislation and authorities) - and we have to mention that audits may refer to even 10 years behind the current financial year. Following normative analysis, equation (1) transforms into a more accurate form, reflecting better Greek private firms' free cash flows:

FCFF $=$ Distributable profit $+($ Unusual and non-recurring items + Tax auditing differences + Depreciation $)$

$$
+ \text { Int(1- tax rate) - InvFixCapital - InvWorkingCapital }
$$

\section{Practical Example}

Now, let us clarify the above type and reasoning with an example of a real private firm, whose statements are being published every year. This company is a hotel firm (let us call it HOTEL SA) and at the tables below basic elements for our analysis are presented, taken from its Balance Sheet, Income Statement and Table of Income Distribution (financial year 2014—and 2013 only for estimating InvFixCapital and InvWorkingCapital). The firm's name and full data can be provided by the authors, if needed. 
Table 5

Balance Sheet Elements of HOTEL SA

\begin{tabular}{lll}
\hline & & Years \\
\hline Items & 2014 & 2013 \\
\hline Assets & & \\
\hline Fixed assets & $1,447,411.15 €$ & $1,429,382.79 €$ \\
Current assets & $782,180.69 €$ & $618,865.22 €$ \\
Accounts receivable & $118,430.48 €$ & $122,328.79 €$ \\
Cash & $662,480.73 €$ & $495,448.10 €$ \\
Other items & $1,269.48 €$ & $1,088.33 €$ \\
Total assets & $1,238,719.78 €$ & $1,133,141.54 €$ \\
Liabilities and equity & & \\
Equity & $1,055,529.32 €$ & $1,027,129.55 €$ \\
Liabilities & $182,114.72 €$ & $104,921.45 €$ \\
Current liabilities & $182,114.72 €$ & $104,921.45 €$ \\
Other items & $1,075.75 €$ & $1,090.55 €$ \\
Total liabilities and equity & $1,238,719.79 €$ & $1,133,141.55 €$ \\
\hline
\end{tabular}

Table 6

Income Statement and Table of Income Distribution of HOTEL SA

\begin{tabular}{ll}
\hline & 2014 \\
\hline Income statement & $188,402.48 €$ \\
\hline Ebitda and unusual items & $14,743.76 €$ \\
Unusual profit & $203,146.24 €$ \\
Ebitda & $0.00 €$ \\
Net depreciation expense & $203,146.24 €$ \\
Ebit & $-11,894.95 €$ \\
Net interest expense & $215,041.19 €$ \\
Net income before taxes & \\
\hline Distributable income statement & $215,041.19 €$ \\
\hline Net income before taxes & $288,490.16 €$ \\
Last year's profit & $66,191.93 €$ \\
Total taxes & $57,576.03 €$ \\
Income tax & $8,615.90 €$ \\
Other non-operational taxes & $437,339.42 €$ \\
Distributable income & $148,849.26 €$ \\
Distributable income from year 2014 only & \\
\hline
\end{tabular}

At first some important remarks are necessary: regarding the Balance Sheet, HOTEL SA presents no long-term debt. Furthermore, looking at the Income Statement, it seems that the firm has net profits from interest (as the negative net interest expense indicates). Finally, in distributable income an item is included (Last Year's Profit), which for the purpose of valuation should be omitted. Nevertheless, not including it in the final distributable income does not affect total taxes, since this is income that was taxed in the previous years. The tax rate itself (not knowing the statutory tax rate) can be calculated using a simple form of the average tax rate (total tax burden/taxable income): in the example is up to 31\%. InvWorkingCapital—excluding cash—is negative and it may, or may not be included in the analysis (although we finally include it). The formula (8), using the numbers above, produces the following result: 


$$
\begin{gathered}
\text { FCFF }=148,849.26+(14,743.76+0+0)+(-11,894.95)(1-0.31)-18,028.36-(-80,910.43)= \\
148,849.26+14,743.76-8,207.52-18,028.36+80,910.43=218,267.57
\end{gathered}
$$

\section{Limitations of the Model}

The produced model contains certain limitations that need to be clarified. At first, the potential information for a proper appraisal of a private firm in Greece is rather limited up to the level of the published statements. These statements are a simple form of Balance Sheet, Income Statement and Table of Income Distribution. So, there is not any chance for an appraiser to be more accurate a priori, unless he/she communicates with the owners and gets private accounting data. However, adjusting the nominator is a useful tool in the first place to come to a result of value. Furthermore, it is necessary to report that many of these items that we have taken in response may contain false elements in them. Again, a further examination of all items would require private accounting data, not available for any external appraiser that does not have the consensus of the owner of the firm for the appraisal.

\section{References}

Bajaj, M., Denis, D. J., Ferris, S. P., \& Sarin, A. (2001). Firm value and marketability discounts. Journal of Corporation Law, 27(1).

Damodaran, A. (2005). Marketability and value: Measuring the illiquidity discount. Available at SSRN 841484.

Franco, G. D., \& Zhou, Y. (2011). Accounting adjustments and the valuation of financial statement note information in 10-k filings. Accounting Review, 86(5), 1577-1604.

Farber, A., Gillet, R., \& Szafarz, A. (2006). A General formula for the WACC. International Journal of Business, 11(2), $211-218$.

Feldman, S. J. (2005). Principles of private firm valuation (Vol. 251). Hoboken, NJ: John Wiley \& Sons.

Feltham, G. A., \& Ohlson, J. A. (1995). Valuation and clean surplus accounting for operating and financial activities. Contemporary Accounting Research, 11(2), 689-731.

Frankel, R., \& Lee, C. M. C. (1998). Accounting diversity and international valuation. Ann Arbor 1001 (1999), 48109-1234.

Friedman, M. L. (2014). Business valuation-Recasting the financial statements. Retrieved from http://www.rrbb.com/wp-content/uploads/2014/09/businessvaluation.pdf

Ginoglou, D. (2014). Tax accounting 2. Thessaloniki, Greece: Ginoglou D. Publications.

Lhaopadchan, S. (2010). Fair value accounting and intangible assets: Godwill impairment and managerial choice. Journal of Financial Regulation and Compliance, 18(2), 120-130.

Schilit, H. M. (2010). Financial senanigans: Detecting accounting gimmicks that destroy investments (corrected November 2010). CFA Institute Conference Proceedings Quarterly, 27, 67-74.

Stowe, J. D., Robinson, T. R., Pinto, J. E., \& McLeavey, D. W. (2007). Equity asset valuation (4th ed.). Hoboken, NJ: John Wiley \& Sons.

Tham, J., \& Vélez-Pareja, I. (2004). Principles of cash flow valuation: An integrated market-based approach. Academic Press. 